\title{
Consonant and vowel perception and production: Early English-French bilinguals and English monolinguals
}

\author{
MOLLY MACK \\ University of Illinois, Urbana, Illinois
}

\begin{abstract}
This study is a comparative analysis of the English phonetic systems of 10 fluent adult EnglishFrench bilinguals who acquired their two languages prior to age 8 and who were English-dominant, and of 10 adult English monolinguals. The objective of the study was to determine whether or not early English-dominant bilinguals perceive and produce speech as English monolinguals do. Discrimination and identification tests of synthetic /d-t/ and /i-I/ continua and speech production tests revealed that the bilinguals' discrimination and production of $/ \mathrm{d} / \mathrm{and} / \mathrm{t} /$ and their production of $/ /$ did not differ significantly from the monolinguals'. However, the bilinguals' identification of $/ \mathrm{d}-\mathrm{t} /$ and $/ \mathrm{i}-\mathrm{I} /$ and one aspect of their production of $/ \mathrm{i} /$ did differ significantly from that of the monolinguals. The present results indicate that early bilingualism can yield monolinguallike performance in at least one of the bilinguals' languages, but only with respect to certain aspects of the phonetic system. These findings are viewed in light of sound-class distinctions, the perception-production dichotomy, and bilingual phonetic transfer and restructuring.
\end{abstract}

An abiding concern in bilingual research is whether or not individuals who acquire two languages in early childhood possess phonetic systems like those of monolingual speakers. One view is that such individuals (commonly referred to as "early bilinguals") are capable of acquiring complete control of a second-language phonetic system (Lenneberg, 1967; Penfield, 1953; Penfield \& Roberts, 1959; Seliger, 1978) and, indeed, that they may be entirely monolingual-like in both of their languages (Baetens Beardsmore, 1986). An opposing view is that early bilinguals experience no particular phonological advantage and, in some respects, may be at a disadvantage compared to late (adolescent or adult) bilinguals (Ekstrand, 1976; Snow \& Hoefnagel-Höhle, 1977, 1978). A position intermediate to these is that, although early bilinguals are more likely than late bilinguals to perceive and/or produce their languages in a monolingual-like manner (Asher \& García, 1969; Fathman, 1975; Larew, 1961; Oyama, 1976, 1982; Seliger, Krashen, \& Ladefoged, 1975; Tahta, Wood, \& Loewenthal, 1981a, 1981b), they still may not function exactly as monolinguals do. For example, in a recent study of Spanish-English bilinguals, Flege and

I wish to thank Sheila Blumstein for her ever-helpful advice on and support of this project, Philip Lieberman and Michel Paradis for their indespensable counsel, and John Mertus for his speech programs and valuable assistance. Sincere thanks are also extended to James E. Flege for his insightful comments on an earlier draft and to the editor and reviewers for their pertinent and appreciated comments and suggestions. Any errors or omissions remaining are the responsibility of the author. Portions of this project were funded by a Helen Swallow Richards Endowed Fellowship from the American Association of University Women. Correspondence may be addressed to Molly Mack, Division of English as an International Language and Department of Linguistics, 3070 Foreign Languages Building, 707 S. Mathews Ave., University of Illinois, Urbana, IL 61801.
Eefting (1987b) observed that voice onset time (VOT) production among early acquirers of English was similar, but not identical, to that of age-matched English monolinguals. These results are consistent with those of Caramazza, Yeni-Komshian, Zurif, \& Carbone (1973), Mack (in press), and Williams (1979).

In light of these findings, the present study was designed to test the hypothesis that the speech perception and production of early bilinguals approximates, but does not match, that of monolinguals. To this end, two speech perception and production experiments in English were conducted to compare the phonetic system of fluent adult English-French early bilinguals who were dominant in English with that of adult English monolinguals. ${ }^{1}$

Although it is widely held that bilinguals' nondominant (weaker) language is not monolingual-like largely due to the effects of transfer from the dominant language, it is generally assumed that the dominant language remains "intact"' (see, however, Williams, 1979). Thus, if it were found that early bilinguals do not perceive and/or produce their dominant language as monolinguals do, this would suggest that phonetic transfer is an inevitable consequence of bilingualism. If, however, it were found that early bilinguals do perceive and/or produce their dominant language as do monolinguals, this would suggest that phonetic transfer does not occur (from the nondominant to the dominant language), and would thus reveal that early dual-language acquisition can yield monolingual-like performance at least in the bilinguals' dominant language. Such a study is important in view of the fact that no previous study has obtained extensive phonological/phonetic data from adult early bilinguals.

The decision to utilize only tests of English was made for three reasons. First, the objective of the study was 
to determine whether or not the dominant language of early fluent bilinguals was like that of monolinguals. It has long been established that consistent and pervasive differences may be found when the nondominant language of bilinguals is compared to the same language among monolinguals. However, what has not been well understood is the extent to which the dominant language of early bilinguals is monolingual-like. Second, it was believed that an English-only design would provide the strongest possible test of the null hypothesis, for it ensured that the subjects remained in an English-language set throughout all test administrations. Elman, Diehl, and Buchwald (1977) and Flege and Eefting (1987a) have demonstrated that inducement of specific language sets can significantly influence perceptual performance in stop-consonant identification tasks. Thus, in this study, the attempt was made to maintain an English-language set by using tests administered entirely in English by a native speaker of English. Third, if the bilinguals' French had also been tested, it would not have been meaningful in the absence of French monolingual data comparable to that obtained from the (educated) English monolinguals in the present study, and it was not possible to locate age-matched educated French monolinguals to whom the tests could be administered. Furthermore, it is likely that problems of internal validity would have arisen in conducting $/ \mathrm{i}-\mathrm{I} /$ identification and production tests with French monolinguals, given that a phonemic /I/ does not exist in French. In addition, the idea of using data from French-dominant subjects was rejected because of the possibility that their English would have exhibited marked influences from French. (Indeed, a previous / $\mathrm{i}-\mathrm{I} /$ identification and production study conducted with 10 adult Korean-English bilinguals revealed that performance was highly variable and, for some subjects, was no better than chance, even though all the subjects had begun studying English between the ages of 12 and 14 and were studying in the U.S. when tested [Mack, 1985].

Both stop-consonant and vowel tests were used because differences in the manner in which stop consonants and vowels are perceived and produced have been well documented (Fry, Abramson, Eimas, \& Liberman, 1962; Liberman, Cooper, Shankweiler, \& Studdert-Kennedy, 1967; Pisoni, 1973; Repp, Healy, \& Crowder, 1979; Stevens, Liberman, Studdert-Kennedy, \& Öhman, 1969; also see Lieberman \& Blumstein, 1988, chap. 8). Nonetheless, prior to the present study, no comparative investigation of bilinguals and monolinguals has been undertaken in which the same subjects have participated in perception and production tasks involving both consonants and vowels.

\section{EXPERIMENT 1 PERCEPTION AND PRODUCTION OF /d-t/}

\section{Method}

Subjects. The subjects were 10 English-French bilinguals and 10 English monolinguals, with 7 females and 3 males in each group. The mean age of both groups was 21 years (bilinguals' range =
19-32 years; monolinguals' range $=18-27$ years). At the time of testing, all subjects were, or had recently been, students at Brown University. The subjects were recruited through advertisements placed on campus and were paid for their participation. Prior to the experiment, the subjects completed detailed questionnaires and, after the experiment, the subjects' speaking and reading English and French skills were judged by native speakers. The subjects were also rated as either monolinguals or bilinguals by a group of native speakers of English.

These generalizations emerged from the assessment of the bilinguals: (1) all had acquired English and French in early childhood, with half acquiring English as their first language (L1); (2) they rated themselves as being, in general, almost completely nativelike in English but somewhat less so in French; (3) their English was judged to be better than their French; (4) all were judged native speakers of English, and 1 was also judged a native speaker of French; and (5) no significant difference emerged in the ratings of the subjects as monolinguals or bilinguals. In addition, informal discussion with the bilinguals revealed that, at the time of testing, all used French and English regularly, but that they used English more extensively. Taken together, these data indicate that the bilinguals were, overall, dominant in English. (For further information about the performance of these subjects in English semantics and syntax experiments, see Mack, 1986.)

More specifically, the bilinguals' questionnaire responses revealed that all had acquired French and English prior to age 8, with a mean age of 4.5 years at the onset of the second language (L2). English was the L1 of 5 of the bilinguals and French was the L1 of 4. One bilingual acquired both languages concurrently in infancy. ${ }^{2}$ For 5 of the bilinguals, both parents were native speakers of English; for 3 , both parents were native speakers of French; for 2, one parent was a native speaker of English and one was a native speaker of French. Exposure to, and acquisition of, the L2 occurred in the home, in the environment, and/or in preschool and grade school in the U.S., Canada, or Europe.

The monolinguals' questionnaire responses revealed that all had had 1 to 3 years of formal foreign-language training. All had been raised in monolingual English homes and considered themselves monolingual.

The bilinguals also completed a self-evaluation questionnaire consisting of a subset of questions used by the Foreign Service Institute to assess $L 2$ proficiency. The answers to these questions were scored such that the highest score attainable was 13 (the score of a native speaker). Also included was a 10-point global self-rating scale on which 1 represented minimal proficiency and 10 represented native-speaker proficiency. The highest combined self-evaluation score attainable in either language was 23 . The bilinguals' mean score in English was 20.90 (range $=16-23, S D=2.33$ ); in French it was 16.60 (range $=12-23 ; S D=3.84$ ). Seven of the bilinguals rated themselves as more proficient in English than in French. Of the 3 who did not, 1 rated himself as equally proficient in both languages, and 2 rated themselves as only slightly more proficient in French (but these 2 were not judged as native speakers by native French judges; see below).

Recordings of the bilinguals were also made as they spoke on an assigned topic and read English and French passages. At a later date, a linguistically trained native-English speaker (not the experimenter) rated the bilinguals' English, and 3 native speakers of French rated their French. Ratings of English and French accent and fluency were made on a 10-point scale as described above. In addition, the judges noted whether or not each subject sounded like a native (monolingual) speaker.

The English-speaking judge gave the bilinguals a mean rating of 9.3 in English and indicated that all sounded like native speakers of English, whereas the French judges gave the bilinguals a mean rating of 7.3 in French and indicated that only 1 (M.T., the subject who rated himself as equally proficient in both languages) sounded like a native speaker of French. The 2 bilinguals who rated them- 
selves as being slightly more proficient in French were given lower mean ratings in French than in English by the judges.

In addition, because a number of researchers have demonstrated that native listeners are quite capable of detecting accents or deviations from their own internalized phonetic norms (Asher \& García, 1969; Brennan \& Brennan, 1981; Brennan, Ryan, \& Dawson, 1975; Flege, 1984), it was deemed important to determine whether or not the bilinguals could be detected as being bilingual. Thus, 11 native speakers of American English were presented with recordings of the 20 subjects reading an English-language passage of approximately 150 words (recordings were dubbed versions of those already obtained from the subjects as part of the general language-proficiency evaluation). The passages were randomized with a 15-sec silent interval inserted between each. Two tapes were made (each with 10 subjects), and presentation of the two tapes was counterbalanced among raters. Prior to listening to the tape recordings (presented over headphones with high-quality equipment), the raters were told that some of the speakers were English monolinguals and some were bilingual speakers of English and another (unspecified) language. As they listened to the recordings, the raters had before them printed versions of the passages and a description of the rating scale endpoints 1 and 10. ("1 $1=\mathrm{I}$ am fairly certain that the speaker is bilingual. I perceive some evidence of an accent or other features which indicate bilingualism; $10=\mathrm{I}$ am extremely certain that the speaker is monolingual. I perceive no evidence of an accent or other features which indicate bilingualism."') Endpoint descriptions were designed to encourage the raters to respond to any detectable differences between the two groups, including differences that might not be perceived as strictly accentual.

The raters gave the bilinguals a mean rating of 5.43 and the monolinguals a mean of 6.84. A two-way (group $\times$ rater) repeatedmeasures ANOVA revealed no significant difference in the groups' ratings, a highly significant difference among raters $[F(10,180)=$ $4.44, p<.0001$, and no significant group $\times$ rater interaction. Additional analysis of the bilinguals' scores was carried out to determine whether or not any were rated significantly differently from any others. A one-way ANOVA revealed that there was a significant difference in the bilinguals' ratings $[F(9,100)=10.26$, $p<.001]$. A Scheffé post hoc test indicated that 2 bilinguals (M.E. and M.T.) received ratings that were significantly lower than those of at least some of the other bilinguals'. Although these findings suggest no significant difference in the speech production of the monolinguals and bilinguals, they must be interpreted cautiously. Some of the monolinguals received quite low ratings, which reveals that the raters could not reliably identify all monolinguals as such.

Stimulus Selection. The stop consonants $/ \mathrm{d} /$ and $/ \mathrm{t} / \mathrm{were}$ selected because, although both are phonemes in English and French, their VOTs are associated with different voicing categories in the two languages. ${ }^{3}$ That is, most studies of English VOT have found that if $/ d /$ is prevoiced, it is prevoiced inconsistently, and that if it is not prevoiced, it has an average VOT of about +15 to $+25 \mathrm{msec}$ (Flege \& Eefting, 1986; Lisker \& Abramson, 1964). In contrast, the French $/ d /$ is more consistently prevoiced, and when not prevoiced, has an average VOT of +1 to $+15 \mathrm{msec}$ (Caramazza \& Yeni-Komshian, 1974). Furthermore, the English / $t /$ VOT is about +70 to +85 msec (Flege \& Eefting, 1986; Lisker \& Abramson, 1964; Zlatin \& Koenigsknect, 1976), whereas the French / $t$ / VOT is about +25 msec (Caramazza \& Yeni-Komshian, 1974; Caramazza et al., 1973; Delgutte, 1986).

\section{Perception}

Stimuli. A 16-member synthetic/da-ta/ VOT continuum was generated with a parallel-synthesis program (Klatt, 1980) modified for the Brown University Linguistics Laboratory. The stimuli were synthesized on a PDP 11/34 computer at a 10-kHz sampling rate and were low-pass filtered at $4.5 \mathrm{kHz}$ during output. Endpoint parameter values for /da/ appear in Table 1. (Unless stated otherwise, parameters for all stimuli were identical.) VOTs ranged from
Table 1

Endpoint Parameters: Synthetic $/ \mathrm{da} /($ VOT $=-60 \mathrm{msec}$ )

\begin{tabular}{|c|c|c|c|c|c|c|c|c|c|c|}
\hline \multirow[b]{2}{*}{$\mathrm{msec} \rightarrow$} & \multicolumn{3}{|c|}{ Prevoicing } & \multirow{2}{*}{$\frac{\text { Burst }}{0}$} & \multicolumn{4}{|c|}{ Transition } & \multirow[b]{2}{*}{+260} & \multirow{2}{*}{$\begin{array}{l}\text { End } \\
+300\end{array}$} \\
\hline & -60 & -15 & -5 & & +5 & +10 & +15 & +50 & & \\
\hline Fl & 250 & & 250 & 500. & & & & .720 & & 720 \\
\hline $\mathrm{F} 2$ & 500 & & 500 & 1700 & & & & 1240 & & 1240 \\
\hline F3 & 1500 & & 1500 & 2800 . & & & & 2500 & & 2500 \\
\hline F4 & 3600 & & & & & & & & & 3600 \\
\hline F5 & 3850 & & & & & & & & & 3850 \\
\hline B1 & 90 & & & & & & & & & 90 \\
\hline B2 & 500 & & 500 & 70 & & & & & & 70 \\
\hline B3 & 500 & & 500 & 110 & & & & & & 110 \\
\hline B4 & 250 & & & & & & & & & 250 \\
\hline B5 & 200 & & & & & & & & & 200 \\
\hline AF & 0 & & 0 & 70 & 0 & & & & & \\
\hline AV & 45 & 45. & 40 & 0 & 0 & 50 & 55 & & 55 & 0 \\
\hline A4 & 0 & & 0 & 40 & 0 & & & & & \\
\hline A5 & 0 & & 0 & 40 & 0 & & & & & \\
\hline
\end{tabular}

Note-F $=$ formant frequency, $B=$ formant bandwidth, $A F=$ frication amplitude, $\mathrm{AV}=$ voicing amplitude, $\mathrm{A}=$ formant amplitude. $\ldots=$ values linearly interpolated at 5-msec intervals (where not specified, parameters retain preceding value).

$-60 \mathrm{msec}$ (prevoiced) to $+90 \mathrm{msec}$ (long-lag voiceless) in 10-msec increments. In all stimuli, the duration from the onset of the consonant release (burst) to the end of the syllable was $300 \mathrm{msec}$. Prevoiced tokens had an additional 10 to $60 \mathrm{msec}$ of voicing prior to burst onset. Voicing amplitude was $0 \mathrm{~dB}$ during the burst in all stimuli except that with a 0 -msec VOT, in which voicing was $40 \mathrm{~dB}$ from 0 to +5 msec. For nonprevoiced stimuli, aspiration (with an amplitude of $55 \mathrm{~dB}$ ) began at $+10 \mathrm{msec}$ and continued until it was replaced by voicing at the temporal value corresponding to the VOT of the stimulus. F0 was set at $120 \mathrm{~Hz}$ during prevoicing and through the burst. At $+10 \mathrm{msec}$, it was set to $103 \mathrm{~Hz}$, then it rose linearly for $25 \mathrm{msec}$ to $125 \mathrm{~Hz}$. From +35 to $+95 \mathrm{msec}$, F0 remained at $125 \mathrm{~Hz}$, then fell to $50 \mathrm{~Hz}$ at the end of the syllable. Prior to recording, $\mathrm{dB}$ levels were gain-control adjusted so that peak amplitudes of all stimuli were within $2 \mathrm{~dB}$ of one another on the VU meter.

Procedure. For discrimination, a two-step AX paradigm was used with the members of each stimulus pair drawn from the continuum at 20 -msec intervals. Thirty pairs (16 same, 14 different) were presented in random order 10 times, yielding a total of 300 trials. There were 10 trials per block, with an interstimulus interval (ISI) of $1 \mathrm{sec}$, an intertrial interval (ITI) of $4 \mathrm{sec}$, and an interblock interval (IBI) of $10 \mathrm{sec}$. For identification, the 16 stimuli were presented in random order 10 times, yielding a total of 160 trials. There were 10 trials per block, with an ISI of $3 \mathrm{sec}$ and an IBI of $6 \mathrm{sec}$. A 10-trial pretest without feedback was given immediately prior to both tests to familiarize the subjects with the procedure.

The subjects were tested individually in a sound-attenuated room in the Phonetics Laboratory at Brown University. Both discrimination and identification tapes were played on an MCI JH-1 10 tape recorder with an NAD or McIntosh stereo amplifier. The subjects listened to stimuli through Superex headphones with the amplitude set at a comfortable level. The discrimination test was administered prior to the identification test, and the two tests were never administered on the same day. For discrimination, the subjects circled " $S$ " (same) or " $D$ " (different) on an answer sheet; for identification, they circled "ta" or "da." The subjects were told to guess, on either test, if they were uncertain. Prior to this and other perception tests, the subjects were told that the stimuli were English sounds, and all instructions were provided in English.

\section{Production}

Materials. The subjects read two randomizations of the 54 English consonant-vowel-consonant (CVC) words listed in Appendix A, yielding a total of 2,160 words for analysis. The subjects 
were recorded in a sound booth with high-quality recording equipment (a Nagra 4.2 tape recorder and a Shure SM 81 microphone).

Procedure. VOTs for word-initial stops were measured after all words were transferred to a PDP 11/34 computer on which they were sampled at $20 \mathrm{kHz}$ and low-pass filtered at $9.0 \mathrm{kHz}$. VOT measurements were derived directly from a VT-11 vector graphics terminal that displayed the speech waveforms. Waveforms were demarcated with lightpen-controlled cursors placed at zero crossings. Durational measurements had a sampling-period accuracy of within $.05 \mathrm{msec}$. The onset of prevoicing was fairly easy to determine: a quasiperiodic low-amplitude waveform appeared and usually continued until the release of the consonant. ${ }^{4}$ The onset of the consonant release was characterized by a brief spike, or burst, followed by a segment of aperiodicity. The cessation of the release was the point at which a positive peak of pulsation occurred.

\section{Results}

Perception. The bilinguals and monolinguals exhibited similar response patterns in discriminating VOT, (Figure 1a). Both groups performed below chance on prevoiced stimuli and both exhibited a sudden increase in percent correct on pairs 7-9 (corresponding to stimuli with VOTs of 0 and $+20 \mathrm{msec}$ ) and on pairs 8-10 (corresponding to stimuli with VOTs of +10 and $+30 \mathrm{msec}$ ). A standardized $\mathrm{d}^{t}$ score was calculated for each subject and a two-way (group $\times$ stimulus pair) repeated-measures ANOVA was conducted on these scores. (This score conversion is recommended as an unbiased index of sensitivity although, as Macmillan, Kaplan, \& Creelman, 1977, noted, the scores obtained may be slightly biased upward in a 2IAX design.) In the computation of $d^{\prime}$, percents of hits and false alarms were converted to $z$ scores. There was no significant difference between groups, but there was a highly significant difference among stimulus pairs $[F(13,234)=22.38, p<.001]$. There was no significant group $\times$ stimulus pair interaction. A post hoc test was not conducted on the finding of a significant difference among stimulus pairs because this result, largely expected, was not of special interest.

The bilinguals' performance in identifying VOT was both similar to and different from that of the monolinguals (Figure 1b). Analysis of the identification data was based upon determining the phonetic boundary between $/ \mathrm{d} /$ and $/ \mathrm{t} /$ using a linear-regression analysis procedure recommended by Eimas, Cooper, and Corbit (1973). (The percent of $/ \mathrm{ta} /$ responses given by each subject to each stimulus was converted to a $z$ score and a least-mean-squares solution was obtained to fit the subject's regression line to the data; the boundary between $/ \mathrm{t} /$ and $/ \mathrm{d} /$ was the value corresponding to a performance score of $50 \%$ and a $z$ score of zero.)

The bilinguals' average boundary was located at stimulus 9.28 , corresponding to a VOT of about $+20 \mathrm{msec}$; the monolinguals' was located at stimulus 8.94. A $t$ test of independent means conducted on the values derived for the crossover points revealed no significant difference between the bilinguals' and the monolinguals' /da-ta/ boundaries. A Kruskal-Wallis $H$ test with correction for ties revealed a significant difference in the slope of the groups' lines $[H=8.742, p<.005$; i.e., there were fewer steep regression lines among the bilinguals than

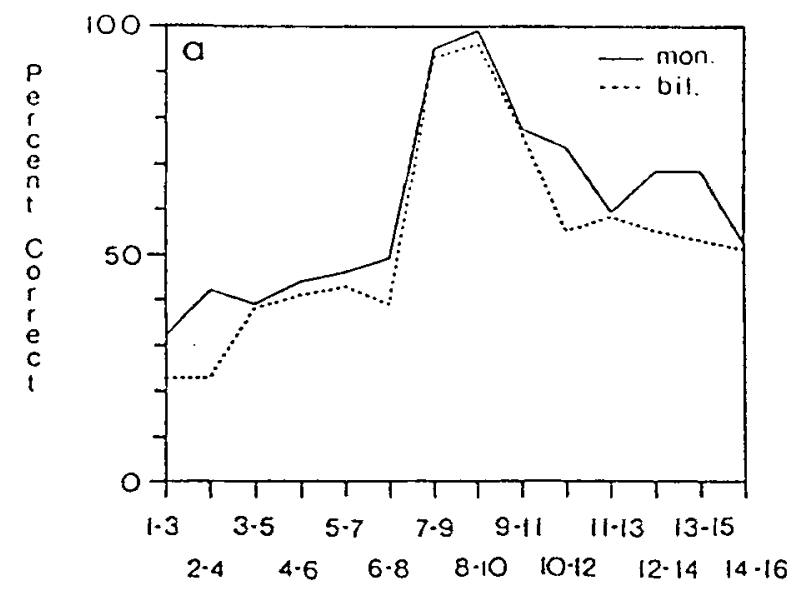

Stimulus Pair

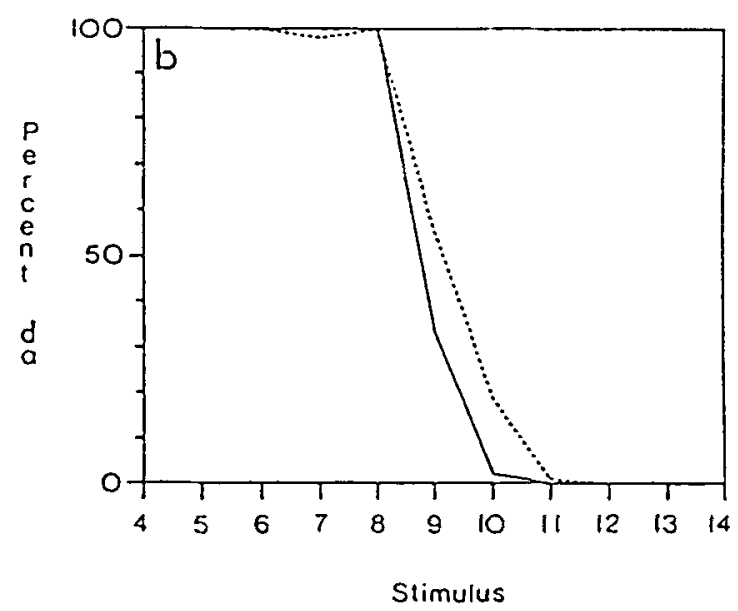

Figure 1. (a) Discrimination functions for synthetic /da-ta/ stimuli in same-different task. Each data point represents the average of 100 responses. (b) Identification functions for /da - ta/ stimuli. Each data point represents the average of 100 responses. Only stimuli 4 to 14 have been presented to facilitate direct comparison with the $11-$ member $/ \mathrm{i}-\mathrm{I} /$ continuum in Figure $3 \mathrm{~b}$ (there was $100 \%$ agreement on responses to Stimuli 1-6 and 12-16).

among the monolinguals] and a nearly significant difference in the fit of the two groups' regression lines $[H=3.580, p=.055$; i.e., the bilinguals' regression lines tended to fit less well than the monolinguals']. In spite of this apparent difference, the lines of both groups fit quite well: the bilinguals' mean $r^{2}$ was .92; the monolinguals' was .97 .

Production. An analysis of the production data revealed that there were no significant differences in the VOTs of the subject groups.

The bilinguals' prevoiced VOT was somewhat shorter than the monolinguals' (Table 2) and, for both groups, prevoicing occurred irregularly. (Eight of the bilinguals and 6 of the monolinguals prevoiced only 0 to 10 tokens each; because of the inconsistency in prevoicing and the relative paucity of prevoiced $/ \mathrm{d} / \mathrm{s}$, a statistical analysis of prevoicing durations was not conducted.) A Mann- 
Table 2

VOTs (in msec)

\begin{tabular}{|c|c|c|c|c|c|c|c|}
\hline \multirow[b]{3}{*}{ Subject } & \multicolumn{3}{|c|}{ Bilinguals } & \multicolumn{4}{|c|}{ Monolinguals } \\
\hline & \multicolumn{3}{|c|}{ Prevoicing } & \multirow[b]{2}{*}{ Subject } & \multicolumn{3}{|l|}{ Prevoicing } \\
\hline & $/ \mathrm{d} /$ & $/ \mathrm{d} /$ & $/ \mathrm{t} /$ & & $/ \mathrm{d} /$ & /d/ & $/ \mathrm{t} /$ \\
\hline A.B. & -86.90 & 16.78 & 84.36 & C.B. & & 18.04 & 68.30 \\
\hline A.O. & -84.15 & 17.01 & 84.83 & C.K. & -87.17 & 17.51 & 92.21 \\
\hline C.C. & -97.18 & 23.61 & 74.85 & I.A. & -118.78 & 21.61 & 79.48 \\
\hline J.A. & & 35.54 & 85.02 & J.S. & -94.40 & 16.22 & 82.96 \\
\hline L.M. & -68.62 & 17.12 & 79.76 & L.K. & -85.75 & 22.70 & 73.48 \\
\hline M.E. & -51.92 & 11.76 & 64.61 & L.L. & & 21.16 & 79.81 \\
\hline M.T. & -100.54 & 21.99 & 86.55 & M.F. & -119.73 & 17.19 & 92.79 \\
\hline N.T. & -86.09 & 26.03 & 101.81 & R.G. & -97.61 & 24.61 & 97.98 \\
\hline P.F. & -76.84 & 19.91 & 71.89 & S.F. & & 26.64 & 79.66 \\
\hline S.J. & -84.98 & 24.70 & 72.47 & T.J. & -115.50 & 15.21 & 100.94 \\
\hline Mean & -82.80 & 21.44 & 80.62 & & -109.69 & 20.09 & 84.76 \\
\hline$S D$ & & 6.60 & 10.37 & & & 3.82 & 10.73 \\
\hline
\end{tabular}

Note-Prevoiced means are weighted. Due to the large intersubject variability in the use of prevoicing, prevoiced /d/ standard deviations are not presented.

Whitney $U$ test revealed no significant difference in the number of prevoiced tokens produced by the groups.

A two-way (group $\times$ phoneme) repeated-measures ANOVA revealed no significant between-group short- or long-lag VOT differences and no significant interaction. In fact, the groups' mean short-lag /d/ VOTs were quite similar $(+21.44$ msec for the bilinguals and $+20.09 \mathrm{msec}$ for the monolinguals) as were their mean / $t /$ VOTs $(+80.62 \mathrm{msec}$ for the bilinguals and $+84.76 \mathrm{msec}$ for the monolinguals). The difference between the VOTs of the two phonemes was highly significant $[F(1,18)=626.49$, $p<.0001]$.

An analysis of words with medial /a/ was also performed to facilitate direct comparison with the perception task that utilized /da-ta/ stimuli. The results revealed values similar to those described above and the same patterns of statistical significance. The /da-ta/ VOTs seemed to overlap somewhat more for the bilinguals than for the monolinguals (Figures 2a and 2b); however, a KolmogorovSmirnov two-sample test revealed no significant differences in the groups' VOT dispersion.

Individual differences in VOT production were also examined. Specifically, measurements for the 3 bilinguals who were deemed by the French judges to have the most native-like French accents in their extemporaneous speech (M.E., M.T., and S.J.) were compared to measurements for the 3 bilinguals judged to have the least native-like French accents (A.B., A.O., and C.C.). It was hypothesized that the more native-like a subject's pronunciation of French, the less likely he or she would be to produce English-like VOTs. However, no systematic differences emerged between these two groups of bilinguals.

\section{Summary}

The perception and production of /d/ and / $t$ / VOTs by 10 early English-French bilinguals and 10 English monolinguals were analyzed. The results of the perception tests revealed no significant differences in the bilinguals' and monolinguals' discrimination of a 16-member synthetic $/ \mathrm{da}-\mathrm{ta} / \mathrm{continuum}$ or in the location of their /d-t/ iden- tification boundaries. However, the bilinguals had fewer steep regression-line functions than did the monolinguals. (The fit of their regression lines was also not as good as the monolinguals', but this difference did not reach sig-
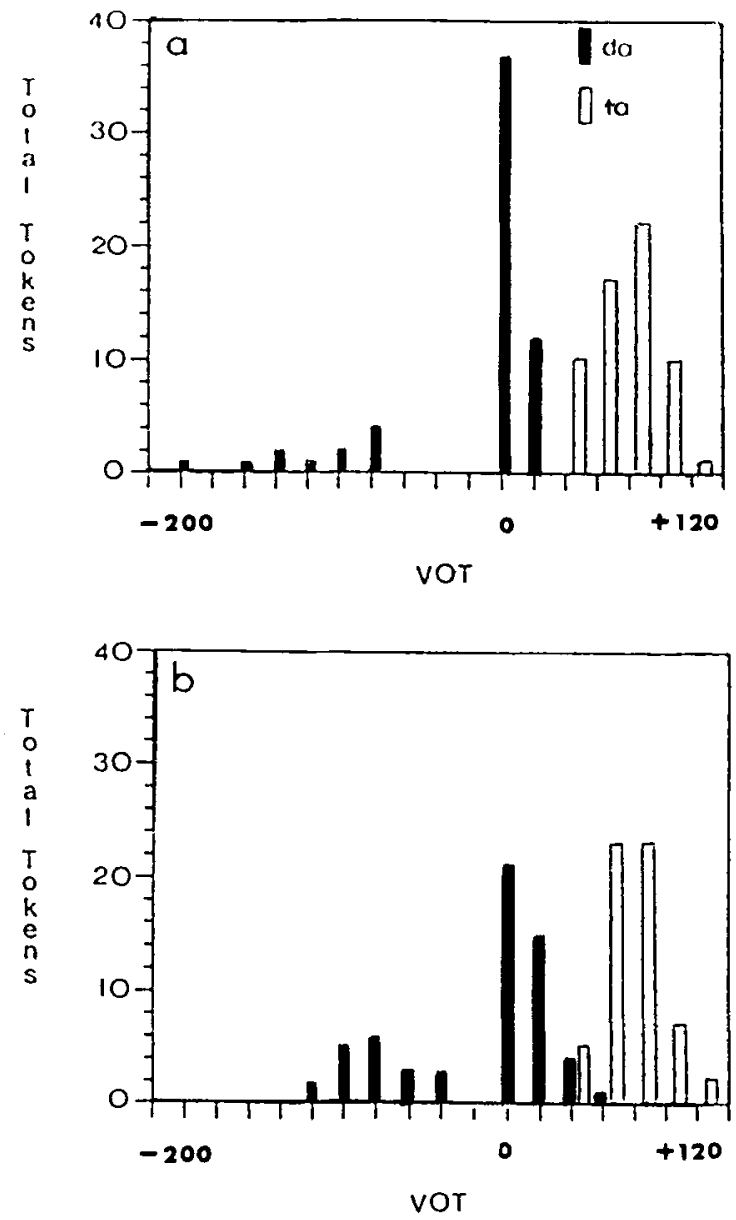

Figure 2. Histograms displaying dispersion of monolinguals' (a) and bilinguals' (b) VOTs for /da/- and /ta/-initial words. Each graph represents 120 tokens. 
nificance.) There were no significant differences in the groups' production performance. That is, they performed similarly with respect to the number of prevoiced tokens in their VOTs for $/ \mathrm{d} /$ and $/ \mathrm{t} /$ (and $/ \mathrm{da} /$ and $/ \mathrm{ta} /$ ), and in the dispersion of VOTs for /da-ta/ tokens. Furthermore, there was no systematic difference in the English VOTs of the bilinguals judged to be least and most native-like in their production of extemporaneous speech in French.

\section{EXPERIMENT 2 PERCEPTION AND PRODUCTION OF /i/ AND /I/}

Experiment 2 was conducted to determine whether or not the pattern of similarities and differences observed between the bilinguals and monolinguals in Experiment 1 would obtain if vowels rather than stop consonants were used in tests of speech perception and production.

\section{Method}

Subjects. The subjects were the same 10 bilinguals and 10 monolinguals who participated in Experiment 1.

Stimulus selection. The $/ \mathrm{i}-\mathrm{I} /$ vowel contrast was utilized because French, unlike English, does not have the phoneme /I/ and because there are spectral and temporal distinctions between the English and the French $/ \mathrm{i} /$. That is, the English /i/ has an F1 that is higher and an F2 that is lower than the F1 and F2 of the French / $/$ / (Delattre, 1964; Peterson \& Barney, 1952). The English /i/ is also sometimes considered a diphthong (Nearey, 1980), whereas the "pure" French /i/ is not (Heffner, 1950); that is, the English / $\mathrm{i} /$ can be characterized as moving from a somewhat intermediate or mid position to a high position. In addition, / $i$ / is one of the longest vowels in English (Peterson \& Lehiste, 1960), but one of the shortest in French (Gottfried, 1984; O'Shaughnessy, 1981).

\section{Perception}

Stimuli. An 11-member synthetic-vowel continuum was generated with the same equipment and procedure described in Experiment 1 , except that a cascade rather than parallel synthesizer was used. Endpoint parameter values appear in Table 3. The stimuli were $250 \mathrm{msec}$ long and were essentially steady state although, from 200 to $250 \mathrm{msec}$, the first three formants were changed slightly to render the vowels more natural sounding. Linear interpolation was used to obtain the formant frequencies for the nine stimuli between

Table 3

Endpoint Parameters: Synthetic /i/ and ///

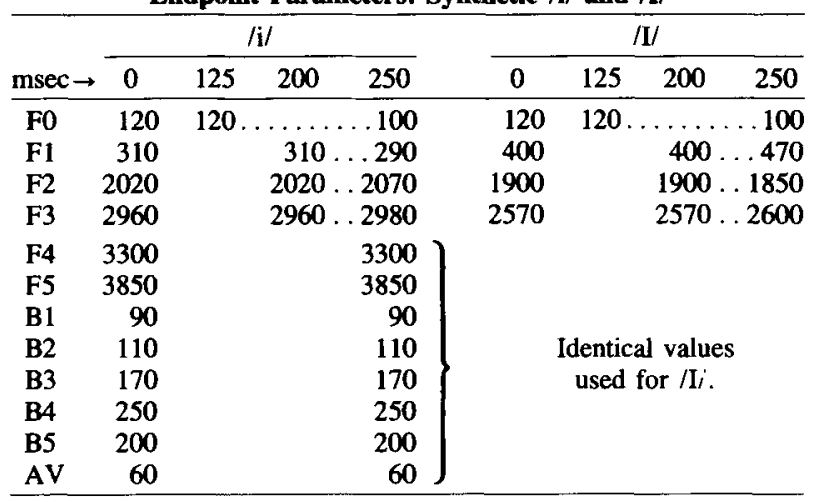

Note $-F=$ formant frequency, $B=$ formant bandwidth, $A V=$ voicing amplitude. $\ldots .=$ values linearly interpolated at 5 -msec intervals (where not specified, parameters retain preceding value). the $/ \mathrm{i} /$ and $/ \mathrm{L} /$ endpoints. Prior to recording, $d B$ levels were gaincontrol adjusted so that stimuli peak amplitudes were within $2 \mathrm{~dB}$ of one another on the VU meter.

Procedure. For discrimination, a two-step AX paradigm was used. Twenty stimulus pairs ( 11 same, 9 different) were presented in random order 10 times each, yielding a total of 200 trials, with 10 trials per block and an ISI of $1 \mathrm{sec}$, an ITI of $4 \mathrm{sec}$, and an IBI of $10 \mathrm{sec}$. For identification, all 11 stimuli were presented in random order 10 times, for a total of 110 trials. There were 10 trials per block, with an ISI of $3 \mathrm{sec}$ and an IBI of $6 \mathrm{sec}$. A 10-trial pretest without feedback was given immediately prior to both tests.

\section{Production}

Materials. The subjects read two randomizations of the 10 English CVC words listed in Appendix B, for a total of 400 words. The recording procedure was identical to that described in Experiment 1.

Procedure. Digitization and acoustic analyses were carried out as in Experiment 1. A number of parameters were examined: vowel duration; F1, F2, and F3 at vowel midpoint; F3-F2 and F2 - F1 at vowel midpoint; F2 at vowel onset and offset; and the extent of F2 change from vowel onset to midpoint and from midpoint to offset. In addition, midpoint $F 1, F 2$, and $F 3$ values were converted to Bark-scale values using the formula proposed by Zwicker and Terhardt (1980):

$$
B=13 \arctan (0.76 f)+3.5 \arctan (f / 7.5)^{2},
$$

where $B$ is the critical band value in Bark and $f$ is the frequency in kilohertz.

The vowel onsets were easy to determine subsequent to stop consonants, for they were exemplified by pitch-period regularity signaling the onset of phonation. When such phonation was obscured (as it sometimes was following $/ \mathrm{h} /$ and $/ \mathrm{s} /$ ), a relatively sudden increase in the amplitude of the waveform was interpreted as the vowel onset. The vowel offset was identified as the point at which a localized decrease in waveform amplitude and/or complexity occurred. Phonation occurring after the vowel offset was not considered part of the vowel, but was interpreted as prevoicing associated with the final voiced consonant.

In obtaining $F 1, F 2$, and $F 3$ values, cursors were placed at the onset and offset of each vowel while a 15-msec full-Hamming window moved automatically across the signal, sampling the waveform at 15-msec intervals and printing plots of F1, F2, F3, and F4 on a Tektronix 4006-1 storage scope with the display limited to $5 \mathrm{kHz}$. Formant-track images were converted to printed copies (via a Tektronix 4631 hard-copy unit) from which formant measurements were derived. Measurements were made carefully by hand with a $15-\mathrm{cm}$ ruler on which $1 \mathrm{~mm}$ was equal to $48 \mathrm{~Hz}$ (rounded to $50 \mathrm{~Hz}$ ) on the printed copy. The temporal midpoints of each vowel were determined by locating the intersection of lines drawn vertically and horizontally between the two central data points in the formant tracks of F1, F2, and F3. Midpoint values were used because it was determined that they most accurately reflected the steady-state portion of the vowels. If a sample point were missing, a straight line was drawn between the two adjacent points and the missing value was interpolated. If a point were missing at the vowel onset or if two adjacent points were missing, no measurement was made. Of the 1,000 potential data points per group, $5.1 \%$ were missing for the bilinguals and $6.5 \%$ were missing for the monolinguals.

\section{Results}

Perception. Discrimination-test results revealed that the bilinguals and monolinguals had somewhat similar response patterns (Figure 3a). Both groups performed, overall, above chance, and both exhibited a slight peak in discrimination at pair 3-5 (the monolinguals had an ad- 

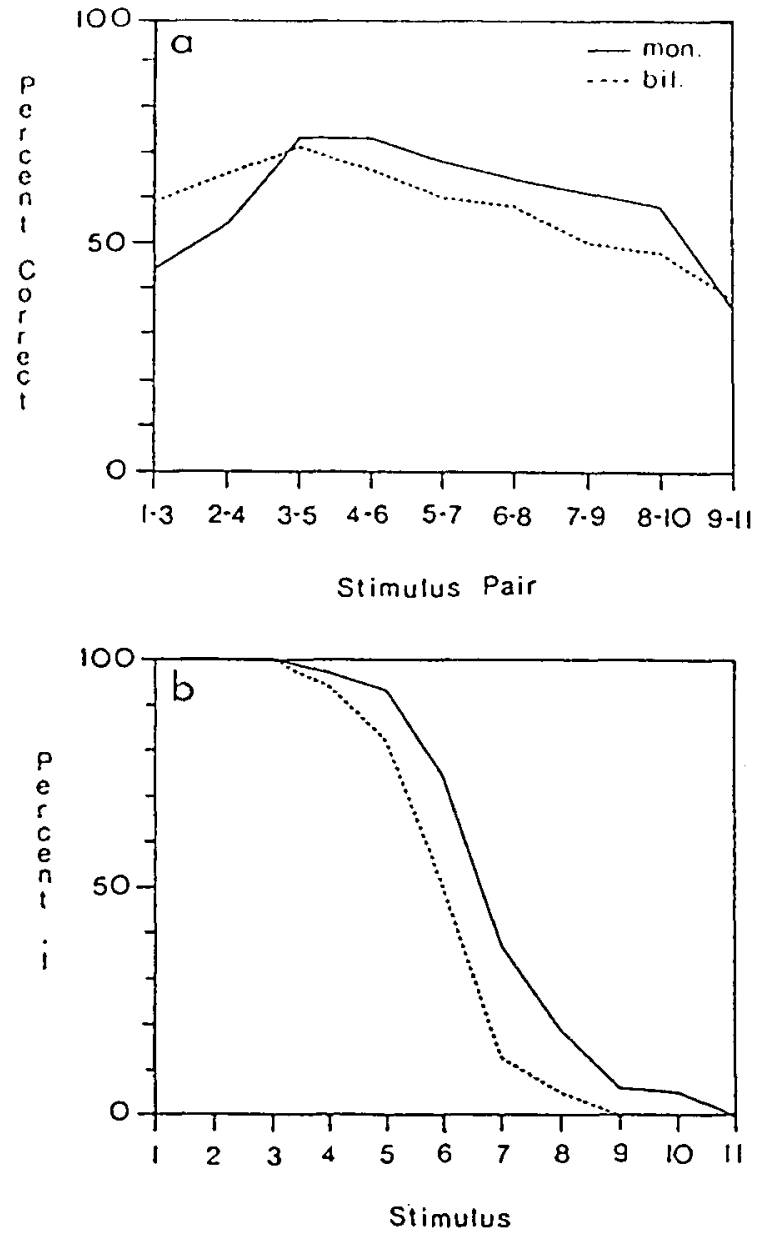

Figure 3. (a) Discrimination functions for synthetic /i-I/ stimuli in the same-different task. Each data point represents the average of 100 responses. (b) Identification functions for $/ i-I /$ stimuli. Each data point represents the average of 100 responses.

ditional small peak at pair 4-6). The values were converted to standardized $\mathrm{d}^{\prime}$ scores and a two-way (group $x$ stimulus pair) repeated-measures ANOVA was conducted. The results revealed no significant difference be- tween the groups, a significant difference among stimulus pairs $[F(8,144)=2.59, p<.01]$, and no significant group $\times$ stimulus pair interaction.

Unlike their discrimination-test responses, the groups' identification-test responses did differ significantly (Figure 3b). As in Experiment 1, responses were converted to $z$ scores and regression lines were fit to each subject's data. The results revealed that the bilinguals' average crossover boundary was at stimulus 5.97 , whereas the monolinguals' was at stimulus 6.79. A $t$ test of independent means revealed a significant difference in the location of the groups' crossover points $[t(18)=2.37$, $p<.03]$. Likewise, a two-way (group $\times$ stimulus) repeated-measures ANOVA revealed a significant difference in the number of vowel stimuli identified as / $i /$ by the two groups $[F(1,18)=5.84, p<.03$; i.e., the bilinguals identified fewer stimuli as / $\mathrm{i} /$ than did the monolinguals]. A Kruskal-Wallis $H$ test revealed no significant difference in the regression-line slope or fit of the two groups. ${ }^{5}$

Production. An analysis of the vowel-production data (Table 4) indicated that the groups' mean /i/ durations were quite similar (244.33 msec for the bilinguals and $251.84 \mathrm{msec}$ for the monolinguals), as were their mean /1/ durations (173.51 msec for the bilinguals and $175.25 \mathrm{msec}$ for the monolinguals). A two-way (group $x$ vowel duration) repeated-measures ANOVA revealed no significant difference between groups, a highly significant difference between vowels $[F(1,18)=187.73$, $p<.001]$, and no significant group $\times$ vowel duration interaction. To normalize speaker rates, a durational ratio was calculated for each subject (Table 4). For both groups, this ratio was nearly identical. That is, for the bilinguals, the duration of $/ \mathrm{I} / \mathrm{was}$ about $71 \%$ of the duration of $/ \mathrm{i} /$; for the monolinguals it was about $70 \%$.

Although spectral analysis revealed that the groups' formant-frequency values for $/ \mathrm{i} /$ (Table 5) and $/ \mathrm{L} /$ (Table 6) were somewhat different, a three-way (group $\times$ vowel $x$ formant) repeated-measures ANOVA revealed no significant difference between groups, and no significant group $\times$ vowel, group $\times$ formant, or group $\times$ vowel $\times$ formant interaction. There was (as expected) a significant

Table 4

Vowel Durations and /I/-/i/ Duration Ratios

\begin{tabular}{|c|c|c|c|c|c|c|c|}
\hline \multirow[b]{2}{*}{ Subject } & \multicolumn{3}{|c|}{ Bilinguals } & \multirow[b]{2}{*}{ Subject } & \multicolumn{3}{|c|}{ Monolinguals } \\
\hline & ii/ & $/ \mathrm{I} /$ & $\%$ & & ij/ & $/ \mathrm{I} /$ & $\%$ \\
\hline A.B. & 237.67 & 146.35 & 61.58 & C.B. & 252.91 & 161.19 & 63.73 \\
\hline A.O. & 240.43 & 176.77 & 73.52 & C.K. & 251.08 & 177.94 & 70.87 \\
\hline C.C. & 267.01 & 197.70 & 74.04 & I.A. & 284.52 & 159.61 & 56.10 \\
\hline J.A. & 226.76 & 161.08 & 71.04 & J.S. & 277.01 & 203.50 & 73.46 \\
\hline L.M. & 313.93 & 194.66 & 62.01 & L.K. & 170.51 & 129.74 & 76.09 \\
\hline M.E. & 243.22 & 200.93 & 82.61 & L.L. & 241.77 & 157.03 & 64.95 \\
\hline M.T. & 209.98 & 164.48 & 78.33 & M.F. & 265.72 & 179.61 & 67.59 \\
\hline N.T. & 238.45 & 154.90 & 64.96 & R.G. & 300.87 & 231.44 & 76.92 \\
\hline P.F. & 229.72 & 162.88 & 70.90 & S.F. & 207.70 & 172.01 & 82.82 \\
\hline S.J. & 236.16 & 175.39 & 74.27 & T.J. & 266.34 & 180.47 & 67.76 \\
\hline Mean & 244.33 & 173.51 & 71.33 & & 251.84 & 175.25 & 70.03 \\
\hline$S D$ & 28.33 & 18.95 & 6.83 & & 38.26 & 27.62 & 7.68 \\
\hline
\end{tabular}

Note-Ratios converted to percentages. 
difference between vowels $[F(1,18)=258.78, p<.001]$ and formants $[F(1,18)=3,303.36, p<.0001]$. An identical pattern of results was obtained from statistical analysis of the Bark-scale data.

An additional analysis, designed to normalize betweensubject formant-frequency variation, entailed obtaining the differences between each subject's mean $F 1$ and $F 2$, and F2 and F3. However, a three-way (group $\times$ vowel $\times$ frequency difference) repeated-measures ANOVA conducted on the groups' /i/ and /I/ F2-F1 and F3-F2 differences and on the differences between the corresponding Barkscale values revealed no significant differences between the bilinguals and the monolinguals. The distribution of the Bark values in the $F 1-F 2$ and $F 2-F 3$ vowel space is shown in Figures 4a-4d. As is apparent, there was considerable similarity in the distribution of the groups' values.

An additional measure of the formant frequencies was conducted of F2 at vowel onset, midpoint, and offset. The results of a three-way (group $\times$ vowel $\times$ F2 location) repeated-measures ANOVA revealed no significant difference between groups and no significant group $\times$ vowel, group $\times$ F2 location, or group $\times$ vowel $\times$ F2 location interaction.

To assess the extent to which /i/ and /I/ exhibited changes in onglide and offglide values, a measure was used based upon the percent of vowels that showed an F2 increase between vowel onset and midpoint, and an F2 decrease between midpoint and offset. That is, the percent of vowels whose F2 increased at least $50 \mathrm{~Hz}$ from vowel onset to midpoint (the steady-state portion) and the percent whose $\mathrm{F} 2$ decreased at least $50 \mathrm{~Hz}$ from midpoint to offset were calculated. A Kruskal-Wallis $H$ test revealed a significant difference in the groups' percent of /i/ F2 values decreasing from vowel midpoint to offset $[H=$

Table 5

Frequency of F1, F2, and F3 at /i/ Midpoint (in Hz)

\begin{tabular}{|c|c|c|c|c|c|c|c|}
\hline \multirow[b]{2}{*}{ Subject } & \multicolumn{3}{|c|}{ Bilinguals } & \multirow[b]{2}{*}{ Subject } & \multicolumn{3}{|c|}{ Monolinguals } \\
\hline & FI & $\mathbf{F} 2$ & F3 & & F1 & F2 & F3 \\
\hline \multicolumn{8}{|c|}{ Males } \\
\hline C.C. & 250 & 2250 & 2850 & C.B. & 260 & 2075 & 2865 \\
\hline M.T. & 350 & 2445 & 3062 & M.F. & 285 & 2510 & 3200 \\
\hline P.F. & 285 & 2335 & 2978 & T.J. & 275 & 2485 & 3056 \\
\hline Mean & 295 & 2343 & 2963 & & 273 & 2357 & 3040 \\
\hline$S D$ & 51 & 98 & 107 & & 13 & 244 & 168 \\
\hline \multicolumn{8}{|c|}{ Females } \\
\hline A.B. & 270 & 2590 & 3293 & C.K. & 365 & 2954 & 3414 \\
\hline A.O. & 255 & 2645 & 3129 & I.A. & 365 & 2725 & 3275 \\
\hline J.A. & 385 & 2669 & 3350 & J.S. & 300 & 2606 & 3200 \\
\hline L.M. & 375 & 2384 & 3250 & L.K. & 335 & 2430 & 3367 \\
\hline M.E. & 360 & 2795 & 3275 & L.L. & 360 & 2694 & 3215 \\
\hline N.T. & 310 & 2580 & 3486 & R.G. & 345 & 2995 & 3661 \\
\hline S.J. & 390 & 2839 & 3571 & S.F. & 372 & 2936 & 3328 \\
\hline Mean & 335 & 2643 & 3336 & & 349 & 2763 & 3351 \\
\hline$S D$ & 56 & 151 & 149 & & 25 & 209 & 157 \\
\hline \multicolumn{8}{|c|}{ Mean-Males and Females Combined } \\
\hline Mean & 315 & 2493 & 3150 & & 311 & 2560 & 3196 \\
\hline$S D$ & 54 & 124 & 128 & & 19 & 226 & 162 \\
\hline
\end{tabular}

Table 6

Frequency of F1, F2, and F3 at /I/ Midpoint (in Hz)

\begin{tabular}{|c|c|c|c|c|c|c|c|}
\hline \multirow[b]{2}{*}{ Subject } & \multicolumn{3}{|c|}{ Bilinguals } & \multirow[b]{2}{*}{ Subject } & \multicolumn{3}{|c|}{ Monolinguals } \\
\hline & F1 & $\mathrm{F} 2$ & F3 & & F1 & $\mathbf{F} 2$ & F3 \\
\hline \multicolumn{8}{|c|}{ Males } \\
\hline C.C. & 385 & 1950 & 2756 & C.B. & 395 & 1833 & 2655 \\
\hline M.T. & 455 & 2080 & 2772 & M.F. & 420 & 2020 & 2822 \\
\hline P.F. & 400 & 2050 & 2650 & T.J. & 460 & 1905 & 2764 \\
\hline Mean & 413 & 2027 & 2726 & & 425 & 1919 & 2747 \\
\hline$S D$ & 37 & 68 & 66 & & 33 & 94 & 8 \\
\hline \multicolumn{8}{|c|}{ Females } \\
\hline A.B. & 455 & 2295 & 2930 & C.K. & 520 & 2400 & 3080 \\
\hline A.O. & 495 & 2175 & 2895 & I.A. & 465 & 2055 & 2865 \\
\hline J.A. & 505 & 2130 & 3081 & J.S. & 475 & 2125 & 2836 \\
\hline L.M. & 475 & 2095 & 2795 & L.K. & 500 & 2095 & 2690 \\
\hline M.E. & 420 & 2215 & 2995 & L.L. & 485 & 2040 & 3085 \\
\hline N.T. & 430 & 2155 & 3025 & R.G. & 435 & 2450 & 3145 \\
\hline S.J. & 425 & 2420 & 3225 & S.F. & 485 & 2410 & 3160 \\
\hline Mean & 458 & 2212 & 2992 & & 481 & 2225 & 2980 \\
\hline$S D$ & JJ & 112 & 139 & & 27 & 185 & 18 \\
\hline \multicolumn{8}{|c|}{ Mean-Males and Females Combined } \\
\hline Mean & 436 & 2120 & 2859 & & 453 & 2072 & 2864 \\
\hline$S D$ & 36 & 90 & 102 & & 30 & 140 & 134 \\
\hline
\end{tabular}

$3.872, p<.05$ ], with the bilinguals producing significantly more vowels (mean $=92.31 \%$ ) with such a decrease than did the monolinguals (mean $=80.39 \%$ ). An additional measure was used to determine the extent of F2 change. This measure was based upon the percent change in hertz between vowel onset and midpoint and between midpoint and offset. A Kruskal-Wallis $H$ test revealed no significant difference between the percent of F2 change in the two groups' production of either /i/ or $/ \mathrm{I} /$.

As in Experiment 1, a separate analysis was conducted of the English production of the 3 bilinguals whose extemporaneous French had previously been judged most native-like and the 3 bilinguals whose extemporaneous French had been judged least native-like. An examination of all analyzed parameters revealed no systematic differences between these two groups of bilinguals.

\section{Summary}

The perception and production of the vowels /i/ and /I/ were analyzed using the same bilinguals and monolinguals who participated in Experiment 1. The results of the perceptual tests revealed no significant difference in the groups' discrimination of an 11-member synthetic /i-I/ continuum or in the slope or fit of the groups' identification functions. However, the groups' $/ \mathrm{i}-\mathrm{I} /$ boundaries were significantly different. That is, the bilinguals identified significantly fewer of the stimuli as $/ \mathrm{i} /$. In production, there were no significant differences in the groups' vowel durations or in their F1, F2, and F3 values (and corresponding Bark values). There were also no significant differences in the groups' $F 2-F 1$ and $F 3-F 2$ values (and corresponding Bark values); in $\mathrm{F} 2$ at vowel onset, midpoint, and offset; or in the extent of absolute F2 change. However, the bilinguals did have a significantly 
greater percentage of /i/ vowels whose $F 2$ decreased from midpoint to offset. Finally, there was no systematic difference in the English vowel production of the bilinguals judged to be least and most native-like in their production of extemporaneous speech in French.

\section{GENERAL DISCUSSION}

\section{Similarities Between Early Bilinguals and Monolinguals}

The English-French bilinguals' early exposure to, and prolonged use of, languages that possess different voicing categories did not measurably influence their VOT discrimination. Their discrimination peak was isomorphic with that of the English monolinguals and they showed no peak in the region of the French VOT boundary. This finding appears to reflect the establishment and maintenance of a monolingual-like perceptual system in English. However, it might be argued that this result does not reflect language-specific effects, but rather is a consequence of psychophysical properties of the stimuli that render a temporal distinction at the English voicing boundary (around $+20 \mathrm{msec}$ ) particularly salient (Aslin
\& Pisoni, 1980; Hirsch, 1959; Miller, Wier, Pastore, Kelly, \& Dooling, 1976; Pastore et al., 1977; Pisoni, 1977). Yet the results of a recent perceptual study utilizing stop-consonant and nonspeech (noise-buzz) stimuli call this claim into doubt (Kewley-Port, Watson, \& Foyle, 1988; see however Pastore, 1988). Moreover, language experience has been shown to influence stop-consonant discrimination (Williams, 1979). Thus, a purely psychophysical account of the bilinguals' discrimination performance does not seem tenable. Rather, it appears that the bilinguals' performance reflects, at least to some extent, their extensive and prolonged exposure to English voicing categories.

The bilinguals' discrimination of the / $\mathrm{i}-\mathrm{I} /$ continuum also appears to reflect a perceptual system similar to that of the English monolinguals. However, Stevens et al. (1969) have observed that subjects' native language can have minimal effects on vowel discrimination. This may be explained by the hypothesis that the short-term memory cues for vowel discrimination are auditory rather than phonetic (Pisoni, 1973). Hence, it could be argued that the bilinguals' pattern of vowel discrimination does not attest to the existence of a monolingual-like perceptual sys-
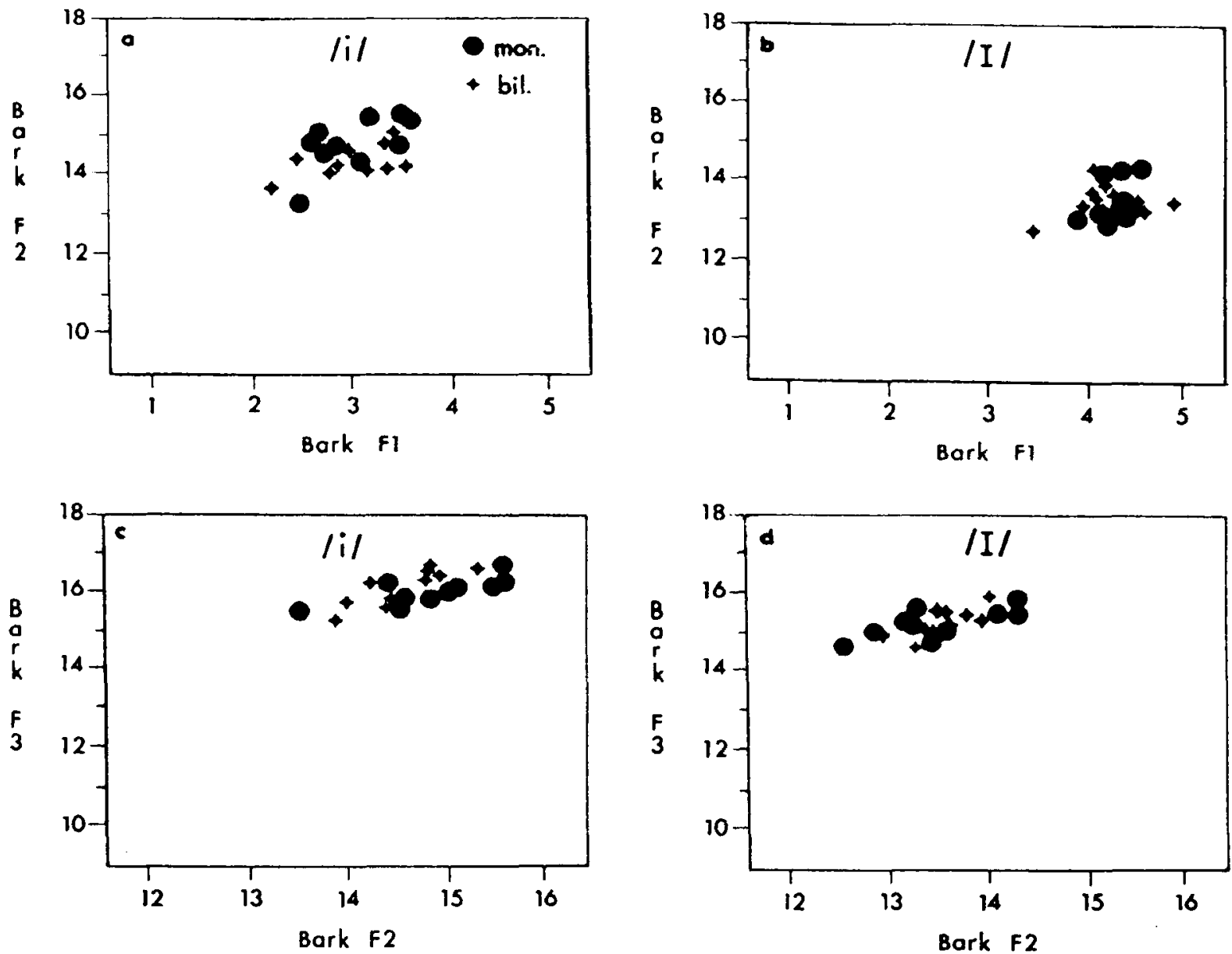

Figure 4. Distribution of Bark-scale values for /i/ (a) and /I/ (b) in the F1-F2 vowel space, and for /i/ (c) and /I/ (d) in the F2-F3 vowel space. 
tem, but is simply a reflection of language-independent auditory memory factors. On the other hand, Repp et al. (1979) have maintained that an all-phonetic model can account for vowel discrimination. They stated that "phonetic mediation for purposes of discrimination is a natural and automatic consequence of [the] inherent priority for the linguistic level of analysis when one exists in stimuli" (p. 143). If this assertion is correct, it would suggest that the bilinguals' discrimination of vowels was mediated by phonetic memory, and that the similarity between their perceptual performance and that of the English monolinguals cannot be attributed solely to the role of auditory memory in distinguishing acoustically dissimilar sounds.

The bilinguals were also similar to the monolinguals in producing English stop-consonant VOT, vowel durations, and nearly all spectral features associated with the vowels.

These results suggest that, with respect to certain types of tasks and acoustic/phonetic parameters, a bilingual's dominant language can remain impervious to the influence of the nondominant language, although this generalization may be more applicable to some early bilinguals than to others. ${ }^{6}$ Nonetheless, it is also possible that other types of tasks, such as speeded classification or judgments of category goodness, might still reveal differences in the performance of subjects such as these.

\section{Differences Between Early Bilinguals and Monolinguals}

In spite of the fact that there were no significant differences in the bilinguals' and monolinguals' discrimination of consonants and vowels and in their production of VOT, vowel duration, and most spectral features associated with the vowels, between-group differences did emerge.

First, although the location of the groups' VOT boundaries did not differ significantly, and the fit of their VOT regression lines showed only a tendency to differ, the slope of their regression lines did differ significantly, with the bilinguals' having significantly fewer steep functions than the monolinguals'. An examination of individual response functions revealed that this difference was attributable to smaller discontinuities in VOT identification among the bilinguals than among the monolinguals in response to Stimuli 8, 9, and 10, corresponding to VOTs of $+10,+20$, and $+30 \mathrm{msec}$. In fact, only 3 of the bilinguals-but 7 of the monolinguals - exhibited a sharp discontinuity in VOT identification responses, manifested as a change from identifying $100 \%$ of the tokens as /d/ to identifying $20 \%$ or fewer as /d/ within one step on the continuum in the region of the category boundary. This result may be due to the fact that, in at least one dialect of French (Canadian French), VOT is a less salient cue to the voicing distinction between homorganic stop consonants than it is in English or in French spoken in France (Caramazza \& Yeni-Komshian, 1974). Thus, in the present study, bilinguals who had been exposed to Canadian French should have displayed greater response uncertainty, manifested in shallower and/or less monotonic
VOT identification functions, than those exposed to French in France. In fact, 2 bilinguals who were speakers of Canadian French did have relatively shallow functionsbut so too did 2 of the 4 speakers of French from France. Thus, it cannot be asserted that the bilinguals' VOT identification functions reflected response uncertainty due to their exposure to French dialects in which VOT is a less salient cue to the /d- $t$ / distinction than it is in English. It may be that the bilinguals' responses reflected uncertainty borne of competition between two systems with different VOT boundaries. Careful study of cues to the /d-t/ contrast in various French dialects would help clarify the source of the bilinguals' apparent perceptual confusion.

Second, the groups also differed in their identification of the / $\mathrm{i}-\mathrm{I} /$ vowel continuum. That is, although the slope and fit of their identification functions were quite similar, the location of their vowel boundaries differed significantly. Specifically, the bilinguals' boundary was closer to the /i/ end of the continuum than was the monolinguals', which reveals that the bilinguals identified fewer of the vowel stimuli as $/ \mathrm{i} /$. Since the French /i/ is more "acute" (peripheral in the high front-vowel space) than its English counterpart, it is reasonable that speakers of French would accept fewer stimuli as instantiations of $/ \mathrm{i} /$ if their exposure to French influenced their perception. Moreover, an examination of individual vowel-identification data revealed that the bilinguals' functions were as monotonic as the monolinguals', thus providing some evidence that the bilinguals' vowel boundary was, in contrast to their VOT boundary, quite stable. This finding is interpreted as evidence that the bilinguals' perception of the $/ \mathrm{i}-\mathrm{I} /$ vowel contrast was influenced by their exposure to French and that, as a result, their English vowel space may have undergone systematic restructuring. Further support for this interpretation might be obtained from the perceptual performance of Frenchdominant French-English bilinguals whose /i-I/ category boundary, it would be predicted, would be located closer to the /i/ endpoint of the continuum than would the boundary of English monolinguals (if, indeed, French-dominant bilinguals could reliably identify /I/-like vowels at all).

A question raised by the identification-test data is this: Why should the bilinguals have performed differently from the monolinguals in consonant and vowel identification but not in discrimination? A possible answer lies in the characteristics of these tests. Unlike the discrimination tests, the identification tests utilized a languagebased response strategy, which may have rendered the identification tests more sensitive indices of linguistic experience and hence of differences between the bilinguals and the monolinguals. Further study may reveal the extent to which stimulus and response-mode characteristics affect the relative accuracy of discrimination and identification responses among early bilinguals.

\section{Sound-Class Distinctions}

The fact that the location of the bilinguals' VOT category boundary was similar to the monolinguals' is of in- 
terest, although there was some evidence that it was less stable. On the other hand, the bilinguals' vowel-category boundary was significantly different from the monolinguals', yet it appeared quite stable. This might be interpreted as evidence that the vowel system is more susceptible to reorganization under the influence of the nondominant language than is the (stop) consonant system.

This interpretation receives some support from the finding that the only difference in the groups' speech production was found in a vowel parameter (i.e., in the percentage of /i/ vowels whose F2 decreased between vowel midpoint and offset). Yet this finding is somewhat problematic. If the French $/ \mathrm{i} /$ is indeed a "purer" vowel than the English /i/, the bilinguals should have produced fewer vowels with a marked F2 offglide than did the monolinguals; at least they should not have produced more of these vowels. Strong conclusions about this finding are further mitigated by the fact that there was no significant difference in the groups' percent of $F 2$ change (in frequency) from $/ \mathrm{i}$ / midpoint to offset. Hence, further interpretation of this finding awaits additional study.

The conclusion that the vowel system is inherently more susceptible to modification than is the stop-consonant system is also not supported by the results of previous studies of voicing-conditioned vowel duration (Mack, 1982) and stop-consonant duration (Mack, 1980-81). Taken together, these two studies revealed that (French-dominant) FrenchEnglish bilinguals displayed more English-like consonant than vowel durations. However, these subjects were late bilinguals, so it is possible that their exposure to English activated perceptual mechanisms and/or production strategies unlike those of early bilinguals. What is at least suggested, then, is that members of different sound classes may not be equally susceptible to phonetic modification.

Related to this notion is a hypothesis proposed by Flege (1987) and Flege and Hillenbrand (1984), termed "equivalence classification." Flege (1987) characterizes this type of classification as "a basic cognitive mechanism which permits humans to perceive constant categories in the face of inherent sensory variability found in the many physical exemplars which may instantiate a category"' (p. 49). He proposes that equivalence classification prevents adult L2 learners from acquiring phones that are similar to those in their L1, but not those that are "new" or dissimilar. This hypothesis predicts, for example, that adult native speakers of English will find it relatively difficult to learn to produce the French vowel $/ \mathbf{u} /$, which is acoustically similar to the English /u/, whereas they will find it easier to learn to produce the French vowel $/ y /$, which has no counterpart in English. The present study provides an opportunity to determine whether or not equivalence classification can be extended to adult early bilinguals.

It could be hypothesized that the English-French bilinguals in the present study should have produced the English phones $/ \mathrm{d} /, / \mathrm{t} /$, and $/ \mathrm{i} /$-which are acoustically similar in French and English-less accurately than the English phone /I/-which has no phonemic counterpart in French and which is acoustically less similar to the French /i/ than is the English /i/. Yet the bilinguals produced all of these phones with essentially equal accuracy. Furthermore, it might be proposed that, if the theory of equivalence classification can be extended to perception, the bilinguals should have performed less accurately in responding to $/ \mathrm{d}-\mathrm{t} /$ than to $/ \mathrm{i}-\mathrm{I} /$. However, this phenomenon was not observed. Thus, as Flege has pointed out (personal communication, 1988), predictions based upon a theory of equivalence classification may not find support in data from early bilinguals, who seem able to produce their dominant language with considerable accuracy.

\section{Perception versus Production}

A number of researchers have observed that, among some subjects, $\mathbf{L} 2$ speech perception may be less accurate than L2 production (Caramazza et al., 1973; Garnes, 1977; Goto, 1971; Mack, 1985; Obler, 1982; Sheldon, 1985; Sheldon \& Strange, 1982). Indeed, Caramazza et al. (1973) stated that "bilinguals appear better able to adapt their production mechanisms than their perceptual mechanisms to the second language" (p. 427). Obler (1982) took a similar position in proposing a dual system for bilingual speech production and a unitary one for perception. Yet this position appears somewhat inconsistent with other findings that, for both $\mathrm{L} 1$ and nonnative stimuli, perception can precede production (Aslin, Pisoni, Hennessey, \& Perey, 1981; Eimas \& Miller, 1980; Eimas, Siqueland, Jusczyk, \& Vigorito, 1971; Flege \& Eefting, 1987b; Menyuk, 1977; Smith, 1973; Trehub, 1973, 1976; Werker \& Tees, 1984).

Among the bilinguals in the present study, the notion that one of the languages was an L2 is not as meaningful as it is in other studies, for these bilinguals acquired their two languages at an early age. Moreover, an inspection of the data revealed no clear difference in the English production or perception of those whose L1 was English and those whose Ll was French. Nonetheless, it is of interest that the general pattern observed supports the claim of some researchers that bilingual production can be more accurate than perception.

A possible explanation for this result was proposed by Sheldon and Strange (1982), who considered evidence that, among Japanese learners of English, the ability to produce the English liquids $/ \mathbf{r} /$ and $/ 1 /$ may exceed the ability to perceive them. Sheldon and Strange implied that this dissociation may be attributable to the effects of L2 pronunciation instruction, which can make "explicit reference to vocal tract gestures [yielding] tactile-kinesthetic perceptual consequences" without necessarily aiding auditory perceptual learning (p. 257). This may be a reasonable account of language acquisition among some L2 learners-especially if the oral proprioceptive mechanisms involved in speech production assist significantly in the regulation of speech (Fucci, Crary, Warren, \& Bond, 1977)-yet it is difficult to apply such an account to the bilinguals in the present study. Seven of the 10 bilingual subjects in this study had received native-speaker English input in the home from at least one parent, and none had ever received formal intensive training in English, so it 
is unlikely that they ever received explicit articulatorily based English instruction.

An alternative explanation for the apparent superiority of production over perception is that the consequences of mispronunciation exceed those of misperception. That is, accented speech is more detectable than "accented" perception, so perhaps sociolinguistic and psycholinguistic factors militate against nonnative production but not nonnative perception. It is also possible that the multiple and often redundant cues available in the speech signal permit bilinguals to perceive English phones nonmonolingually without experiencing significant deficits in comprehension.

Yet a caveat is also in order: It is important to recognize that tests of speech perception require methodologies, task demands, and measurement and evaluation procedures that are inherently different from those used in tests of speech production. Even when attempts are made to design comparable perception and production tests, differences in results may still be due, in whole or in part, to fundamental differences in the nature of the tests employed, rather than in the modalities examined. Thus, because it may be inherently difficult to make meaningful cross-modal comparisons of linguistic behavior, claims about apparent disparities in speech perception and production should be made judiciously.

\section{CONCLUSION}

The present study was designed to compare the English speech perception and production of 10 adult EnglishFrench bilinguals who acquired their two languages in early childhood with that of 10 adult English monolinguals. The objective was to determine the extent to which the English of the bilinguals matched (or approximated) that of the monolinguals.

The results revealed that, in perception, the two groups were nearly indistinguishable with respect to the discrimination of $/ \mathrm{d}-\mathrm{t} / \mathrm{and} / \mathrm{i}-\mathrm{I} /$, the location of the category boundary for $/ d-t /$, and the slope and fit of the $/ i-I /$ regression lines. In production, the groups were also similar with respect to VOT and vowel duration; F1, F2, and F3 (and Bark-scale conversions) at vowel midpoint; F2 at three vowel loci; F2 - F1 and F3-F2 values (and Barkscale conversions); absolute change in F2 from vowel onset to midpoint and from midpoint to offset; and in percent of vowels exhibiting F2 change from onset to midpoint.

In spite of these similarities, however, significant differences between the groups did emerge. In perception, the bilinguals exhibited fewer steep consonant-identification functions than did the monolinguals. An inspection of individual response data revealed that, in contrast to the monolinguals, a majority of the bilinguals had relatively nonmonotonic consonant-identification functions. This finding is interpreted as evidence of response uncertainty induced by differences in the role of voicing cues in French and English and/or by interlingual competition between the different VOT categories of these languages. In vowel identification, the bilinguals identified signifi- cantly fewer vowel stimuli as /i/ than did the monolinguals, yet the groups' functions were equally monotonic. This result is interpreted as evidence of a restructuring of the bilinguals' perceptual system, which is directly attributable to the phonetic/acoustic properties associated with the French /i/. Clearly, such a claim could be strengthened by additional data from monolingual speakers of French, and in future tests of speech perception, alternatives could be found to the type of language-specific identification tests used in the present study, which might thus provide information about the processing of phonemes such as /i-I/ by French monolinguals (or by French-dominant French-English bilinguals).

In production, only one significant difference between the subject groups was found: The percentage of /i/ vowels whose $\mathrm{F} 2$ fell at least $50 \mathrm{~Hz}$ between vowel midpoint and offset was greater for the bilinguals than for the monolinguals. This difference is difficult to interpret, for it seems inconsistent with the data obtained from the absolute change in $\mathbf{F} 2$. Hence, full interpretation of this finding must await further investigation.

It is suggested that the bilinguals' vowel system may have been more susceptible to modification than their consonant system, although it is difficult-if not impossibleto determine that tests of consonant and vowel perception are truly comparable. Furthermore, the bilinguals may have been less accurate in their perception than in their production of English although, again, cross-modal comparisons must be made with caution.

In conclusion, the present results support the hypothesis proposed in the introduction-that the phonetic system of early adult bilinguals approximates, but does not match, that of monolinguals. In some respects, the early English-French bilinguals performed just as the English monolinguals did. In other respects, however, they performed quite differently. In so doing, they revealed that bilingual phonetic transfer and/or systematic restructuring of the phonetic component can occur, at least in the perceptual domain, even in a dominant language used regularly and productively since early childhood.

\section{REFERENCES}

Abramson, A. S., \& Lisker, L. (1985). Relative power of cues: F0 shift versus voice timing. In V. A. Fromkin (Ed.), Phonetic linguistics: Essays in honor of Peter Ladefoged (pp. 25-33). Orlando, FL: Academic Press.

Asher, J. J., \& García, R. (1969). The optimal age to leam a foreign language. Modern Language Journal, 53, 334-341.

Aslin, R. N., \& Pisoni, D. B. (1980). Some developmental processes in speech perception. In G. H. Yeni-Komshian, J. F. Kavanagh, \& C. A. Ferguson (Eds.), Child phonology: Vol. 2. Perception (pp. 6796). New York: Academic Press.

Aslin, R. N., Pisoni, D. B., Hennessy, B. L., \& Perey, A. J. (1981). Discrimination of voice onset time by human infants: New findings and implications for the effect of early experience. Child Development, 52, 1135-1145.

BAETENS BEARDSMORE, H. (1986). Bilingualism: Basic principles. Clevedon, England: Multilingual Matters.

Brennan, E. M., \& Brennan, J. S. (1981). Measurements of accent and attitude toward Mexican-American speech. Joumal of Psycholinguistic Research, 10, 487-501. 
Brennan, E. M., Ryan, E. B., Dawson, W. E. (1975). Scaling of apparent accentedness by magnitude estimation and sensory modality matching. Journal of Psycholinguistic Research, 4, 27-36.

Caramazza, A., \& Yeni-Komshian, G. H. (1974). Voice onset time in two French dialects. Journal of Phonetics, 2, 239-245.

Caramazza, A., Yeni-Komshian, G. H., Zurif, E. B., \& Carbone, E. (1973). The acquisition of a new phonological contrast: The case of stop consonants in French-English bilinguals. Journal of the Acoustical Society of America, 54, 421-428.

Delattre, P. (1964). Comparing the vocalic features of English, German, Spanish and French. International Review of Applied Linguistics, 2, 71-97.

DELGUTTE, B. (1986). Analysis of French stop consonants using a model of the peripheral auditory system. In J. S. Perkell \& D. H. Klatt (Eds.), Invariance and variability in speech processes (pp. 163-177). Hillsdale, NJ: Erlbaum.

Eimas, P. D., CoOper, W. E., \& Corbit, J. D. (1973). Some properties of linguistic feature detectors. Perception \& Psychophysics, 13, 247-252.

Eimas, P. D., \& Miller, J. L. (1980). Discrimination of the information for manner of articulation by young infants. Infant Behavior \& Development, 3, 367-375.

Eimas, P. D., Siqueland, E. R., Jusczyk, P., \& Vigorito, J. (1971). Speech perception in early infancy. Science, 171, 304-306.

EKSTRAND, L. (1976). Age and length of residence as variables related to the adjustment of migrant children, with special reference to second language learning. In G. Nickel (Ed.), Proceedings of the Fourth Intemational Congress of Applied Linguistics (pp. 179-197). Stuttgart, West Germany: Hochschulverlag.

Elman, J. L., Dieht, R. L., \& Buchwald, S. E. (1977). Perceptual switching in bilinguals. Journal of the Acoustical Society of America, 62, 971-974.

Fathman, A. (1975). The relationship between age and second language productive ability. Language Learning, 25, 245-253.

Flege, J. E. (1984). The detection of French accent by American listeners. Journal of the Acoustical Society of America, 76, 692-707.

FLEGE, J. E. (1987). The production of "new" and "similar" phones in a foreign language: Evidence for the effect of equivalence classification. Journal of Phonetics, 15, 47-65.

Flege, J. E., \& EefTiNG, W. (1986). Linguistic and developmental effects on the production and perception of stop consonants. Phonetica, 43, 155-171.

Flege, J. E. \& Eefting, W. (1987a). Cross-language switching in stop consonant perception and production by Dutch speakers of English. Speech Communication, 6, 185-202.

Flege, J. E., \& Eefting, W. (1987b). Production and perception of English stops by native Spanish speakers. Journal of Phonetics, 15, 67-83.

Flege, J. E., \& Hillenbrand, J. (1984). Limits on pronunciation accuracy in adult foreign language speech production. Joumal of the Acoustical Society of America, 76, 708-721.

Fry, D. B., Abramson, A. S., Eimas, P. D., \& Liberman, A. M. (1962). The identification and discrimination of synthetic vowels. Language \& Speech, 5, 171-189.

Fucci, D., Crary, M. A., Warren, J. A., \& Bond, Z. S. (1977). Interaction between auditory and oral sensory feedback in speech regulation. Perceptual \& Motor Skills, 45, 123-129.

GaRnes, S. (1977). Some effects of bilingualism on perception. Papers in Psycholinguistics and Sociolinguistics (pp. 1-10). Columbus: Ohio State University.

GoTo, H. (1971). Auditory perception by normal Japanese adults of the sounds "l" and " $r$." Neuropsychologia, 9, 317-323.

GoTTFRIED, T. L. (1984). Effects of consonant context on the perception of French vowels. Journal of Phonetics, 12, 91-114.

HeFFNER, R-M. S. (1950). General phonetics. Madison: University of Wisconsin Press.

Hirsch, I. J. (1959). Auditory perception of temporal order. Journal of the Acoustical Society of America, 31, 759-767.

Keating, P. A. (1980). A phonetic study of a voicing contrast in Polish. Unpublished doctoral dissertation, Brown University, Providence, RI.

Kewley-Port, D., Watson, C. S., \& Foyle, D. C. (1988). Auditory temporal acuity in relation to category boundaries: Speech and nonspeech stimuli. Journal of the Acoustical Society of America, $\mathbf{8 3}$, 1133-1145.

KLATT, D. (1980). Software for a cascade/parallel formant synthesizer. Journal of the Acoustical Society of America, 67, 971-995.

LAREW, L. A. (1961). The optimum age for beginning a foreign language. Modern Language Journal, 45, 203-206.

LENNEBERG, E. H. (1967). Biological foundations of language. New York: Wiley.

Liberman, A. M., Cooper, F. S., Shankweiler, D. P., \& StuddertKennedy, M. (1967). Perception of the speech code. Psychological Review, 74, 431-461.

Lieberman, P., \& Blumstein, S. E. (1988). Speech physiology, speech perception, and acoustic phonetics. Cambridge, England: Cambridge University Press.

Lisker, L., \& ABRAmson, A. S. (1964). A cross-language study of voicing in initial stops: Acoustical measurements. Word, 20, 384-422.

LiSKER, L., \& ABRAMSON, A. S. (1967) Some effects of context on voice onset time in English stops. Language \& Speech, 10, 1-28.

MACK, M. (1980-81). English and French word-final stop consonants: Monolingual and bilingual production. Brown University Working Papers in Linguistics, 6, 66-72.

MACK, M. (1982). Voicing-dependent vowel duration in English and French: Monolingual and bilingual production. Journal of the Acoustical Society of America, 71, 173-178.

MACK, M. (1985, December). Vowel production and perception in three linguistically dissimilar groups. Paper presented at the meeting of the Linguistic Society of America, Seattle.

MACK, M. (1986). A study of semantic and syntactic processing in monolinguals and fluent early bilinguals. Journal of Psycholinguistic Research, 15, 463-488.

Mack, M. (in press). Phonetic transfer in a French-English bilingual child. Proceedings of the Contact \& Conflict Conference (Vol. 3), Research Centre on Multilingualism, International Symposium, Brussels.

Macmillan, N. A., Kaplan, H. L., Creelman, D. (1977). The psychophysics of categorical perception. Psychological Review, 84, 452-471.

McLaughuin, B. (1981). Differences and similarities between firstand second-language learning. In $\mathrm{H}$. Winitz (Ed.), Native language and foreign language acquisition (pp. 23-31). New York: Annals of the New York Academy of Sciences.

MenyuK, P. (1977). Language and maturation. Cambridge, MA: MIT Press.

Miller, J. D., Wier, C. C., Pastore, R. E., Kelly, W. M., \& Dooling, R. M. (1976). Discrimination and labeling of noise-buzz sequences with varying noise lead times: An example of categorical perception. Joumal of the Acoustical Society of America, 60, 410-417.

NEAREY, T. M. (1980). On the physical interpretation of vowel quality: Cinefluorographic and acoustic evidence. Journal of Phonetics, 8 , 213-241.

OBLer, L. (1982). The parsimonious bilingual. In L. K. Obler \& L. Menn (Eds.), Exceptional language and linguistics (pp. 339-346). New York: Academic Press.

O'Shaughnessy, D. (1981). A study of French vowel and consonant durations. Journal of Phonetics, 9, 385-406.

OYAмA, S. (1976). A sensitive period for the acquisition of a nonnative phonological system. Journal of Psycholinguistic Research, 5, 261-283.

OYama, S. (1982). The sensitive period and comprehension of speech. In S. Krashen, R. Scarcella, \& M. Long (Eds.), Child-adult differences in second language acquisition (pp. 39-51). Rowley, MA: Newbury.

PAstore, R. E. (1988). Burying straw men in imaginary graves: A reply to Kewley-Port, Watson, and Foyle (1988). Journal of the Acoustical Society of America, 84, 2262-2266.

Pastore, R. E., Ahroon, W. A., Baffuto, K. J., Friedman, C., Puleo, J. S., \& FINK, E. A. (1977). Common-factor model of categorical perception. Journal of Experimental Psychology: Human Perception \& Performance, 3, 686-696.

PENField, W. (1953). A consideration of the neurophysiological mechanisms of speech and some educational considerations. Proceedings of the American Academy of Arts \& Sciences, 82, 201-214. 
Penfield, W., \& Roberts, L. (1959). Speech and brain mechanisms. Princeton, NJ: Princeton University Press.

Peterson, G. E., \& Barney, H. L. (1952). Control methods used in a study of the vowels. Journal of the Acoustical Society of America, 24, 175-184.

Peterson, G. E., \& LeHISTe, I. (1960). Duration of syllabic nuclei in English. Journal of the Acoustical Society of America, 32, 693-703.

PisonI, D. B. (1973). Auditory and phonetic memory codes in the discrimination of consonants and vowels. Perception \& Psychophysics, $13,253-260$

PISONI, D. B. (1977). Identification and discrimination of the relative onset of two component tones: Implications for the perception of voicing in stops. Joumal of the Acoustical Society of America, 61, 1352-1361.

Repp, B. H., Healy, A. F., \& Crowder, R. G. (1979). Categories and context in the perception of isolated steady-state vowels. Journal of Experimental Psychology: Human Perception \& Performance, 5, $129-145$.

Seliger, H. W. (1978). Implications of a multiple critical periods hypothesis for second language learning. In W. C. Ritchie (Ed.), Second language acquisition research (pp. 1-19). New York: Academic Press.

Seliger, H. W., Krashen, S. D., \& Ladefoged, P. (1975). Maturational constraints on the acquisition of second language accent. Language Sciences, 36, 20-22.

SHELDON, A. (1985). The relationship between perception of the $/ \mathrm{r} /-/ \mathrm{l} /$ contrast in Korean adults learning English: A reply to Borden, Gerber, and Milsark. Language Learning, 35, 107-113.

Sheldon, A., \& STRANGe, W. (1982). The acquisition of $/ r /$ and $/ \mathbf{l} /$ by Japanese learners of English: Evidence that speech production can precede speech perception. Applied Psycholinguistics, 3, 243-261.

SmITH, N. V. (1973). The acquisition of phonology: A case study. Cambridge, England: Cambridge University Press.

Snow, C., \& Hoefnagel-Höhle, M. (1977). Age differences in the pronunciation of foreign sounds. Language \& Speech, 20, 357-365.

SNOw, C., \& HoefNagel-HöHLE, M. (1978). The critical period for language acquisition: Evidence from second language learning. Child Development, 49, 1114-1128.

Stevens, K. N., Liberman, A. M., Studdert-Kennedy, M., \& Öhman, S. E. G. (1969). Cross-language study of vowel perception. Language \& Speech, 12, 1-23.

TAHTA, S., WoOD, M., \&oewenthal, K. (1981a). Age changes in the ability to replicate foreign pronunciation and intonation. Language \& Speech, 24, 363-372.

Tahta, S., Wood, M., \& Loewenthal, K. (1981b). Foreign accent: Factors relating to transfer of accent from the first language to a second language. Language \& Speech, 24, 265-272.

TREHUB, S. E. (1973). Infants' sensitivity to vowel and tonal contrasts. Developmental Psychology, 9, 91-96.

TREHUB, S. E. (1976). The discrimination of foreign speech contrasts by infants and adults. Child Development, 47, 466-472.

Werker, J. F., \& TeEs, R. C. (1984). Phonemic and phonetic factors in adult cross-language speech perception. Journal of the Acoustical Society of America, 75, 1866-1878.

Wiluams, L. (1979). The modification of speech perception and production in second-language learning. Perception \& Psychophysics, 26, 95-104.

Zlatin, M., Koenigsknect, R. (1976). Development of the voicing contrast: A comparison of voice onset time in stop perception and production. Journal of Speech \& Hearing Research, 19, 93-111.

ZWICKER, E., \& TerHARDT, E. (1980). Analytical expressions for critical-band rate and critical bandwidth as a function of frequency. Journal of the Acoustical Society of America, 68, 1523-1525.

\section{NOTES}

1. The bilinguals are referred to as "English-French" to indicate that English was their dominant language. It is not meant to suggest that it was necessarily their first language. It must be noted that, in most cases, the subjects were not strongly dominant in English.

2. McLaughlin (1981) distinguishes between simultaneous and successive childhood bilingualism, with simultaneous acquisition arising from balanced (and concurrent) exposure to, and use of, two languages from infancy, and successive acquisition occurring when the L2 is acquired around age 3 . He claims that simultaneous acquisition can yield monolingual-like performance, whereas successive acquisition may result in some transfer from the $\mathrm{L} 1$ to the $\mathrm{L} 2$. However, the performance of the simultaneous bilingual (P.F.) in the present study was no more accurate than that of the successive bilinguals who had acquired English as their $\mathrm{L} 2$.

3. VOT is not the sole cue for differentiating voiced and voiceless stops in English, but it is generally agreed to be the dominant one, at least when stops occur in stressed prevocalic position (Abramson \& Lisker, 1985; Lisker \& Abramson, 1967). VOT is the duration between onset of consonant release and onset of vocal fold vibration.

4. Although researchers have traditionally assumed that prevoicing ends just prior to phonation onset, an interesting property of prevoicing was observed here. In many utterances, prevoicing diminished considerably or disappeared altogether in the 10 to $30 \mathrm{msec}$ prior to the burst (also noted by Keating, 1980). Although this interval was silent or of diminished amplitude, it was included in the measurement of the duration of prevoicing. Such utterances also usually exhibited a shortlag VOT characteristic of nonprevoiced utterances. Prevoicing durations reported herein refer only to the period from prevoicing onset to burst onset.

5. Consistent with the findings of previous studies, the responses of both groups to the vowel stimuli were less categorical than to the stopconsonant stimuli, as seen in Figures $1 \mathrm{a}$ and $1 \mathrm{~b}$ versus Figures $3 \mathrm{a}$ and $3 \mathrm{~b}$.

6. Thorough examination of individual differences is beyond the scope of this study. However, it is of interest that bilingual subjects M.T. and N.T. were siblings who claimed to have had nearly identical exposure to their two languages. Yet their speech production parameters were quite dissimilar, as inspection of their VOT and vowel durations reveals.

\section{APPENDIX A}

Test Words: Experiment 1

\begin{tabular}{llll}
\hline deal & teal & & \\
deem & team & Dan & tan \\
dean & teen & doom & tomb \\
Dick & tick & duel & tool \\
dim & Tim & dune & tune \\
dip & tip & dole & toll \\
Dale & tale & dome & tome \\
dame & tame & dote & tote \\
days & taste & dock & tock \\
dead & Ted & dong & tong \\
den & ten & dot & tot \\
desk & test & Doug & tug \\
dab & tab & dub & tub \\
dad & tad & duck & tuck \\
\hline
\end{tabular}

\section{APPENDIX B}

Test Words: Experiment 2

$\begin{array}{ll}\text { bead } & \text { bid } \\ \text { deed } & \text { did } \\ \text { heed } & \text { hid } \\ \text { keyed } & \text { kid } \\ \text { seed } & \text { Sid }\end{array}$

